\title{
In vitro Antimicrobial Effects of Virus Block, Which Contains Multiple Polyoxometalate Compounds, and Hygienic Effects of Virus Block-Supplemented Moist Hand Towels
}

\author{
Katsuaki Dan ${ }^{a}$ Naohiro Katoh ${ }^{b}$ Takaaki Matsuokac Katsuyuki Fujinamid \\ ${ }^{a}$ Research and Development Division, Research Organization of Biological Activity, Tokyo, Japan; ${ }^{b}$ Mitsubishi Pencil \\ Co., Yokohama, Japan; ' Omote Sando Helené Clinic, Tokyo, Japan; ${ }^{\mathrm{d} F S X}$, Inc., Tokyo, Japan
}

\section{Keywords}

Antibacterial · Antiviral · Moist hand towel ·

Methicillin-resistant Staphylococcus aureus .

Polyoxometalate

\begin{abstract}
Background: Historical evidence has verified the multifaceted antiviral efficacy of polyoxometalates (PMs). Methods: We carried out a study to investigate the antimicrobial effects of each of the 5 substances comprising virus block (VB): 3 PMs that have antibacterial and antiviral activity, an antibiotic agent, and an antibacterial agent. We also investigated the effectiveness of the addition of VB to moist hand towels in a study involving 120 volunteers. The time-dependent changes in metal ion concentrations in aqueous VB solution were analyzed using inductively coupled plasma atomic emission spectroscopy. Results: The metal elements in the aqueous VB solution remained stable for 12 weeks without undergoing time-dependent changes. Discussion: Further investigations were performed to study hand hygiene using moist hand towels in daily life settings. To this end, 120 volunteers provided 240 specimens that were used to investigate the presence of antibacterial compounds on the volunteers' hands before and after hand towel use. An aliquot of each specimen was suspended in phosphate-buffered saline
\end{abstract}

and plated on agar media, and the number of colonies formed was counted. Normal bacterial flora found on the hands of the volunteers was investigated before and after the use of 4 different moist hand towels. Conclusions: The effects of VB and PMs were superior to those of commercial moist hand towels, indicating that effective data were obtained that may be useful for the practical application of the tested items.

(c) 2019 The Author(s)

Published by S. Karger AG, Basel

\section{Background}

Polyoxometalates (PMs) are metal oxides that possess a 3-dimensional cluster structure and have excellent longterm stability.

Several hundreds of PMs have been synthesized thus far, and numerous studies on their physiological activities have demonstrated their structure - activity relationships. In general, there are 3 main activities, which are classified as antitumor, antiviral, and antibacterial effects [1-7].

In association with the authors' research institutions, various biological activities of PMs have been reported [8-11]. The mechanisms of antiviral effects differ for various compounds and influence specificity, whereas anti-

\begin{tabular}{|c|c|}
\hline KARGER & $\begin{array}{l}\text { (C) } 2019 \text { The Author(s) } \\
\text { Published by S. Karger AG, Basel }\end{array}$ \\
\hline $\begin{array}{l}\text { E-Mail karger@karger.com } \\
\text { www.karger.com/pha }\end{array}$ & $\begin{array}{l}\text { This article is licensed under the Creative Commons Attribution- } \\
\text { NonCommercial-NoDerivatives } 4.0 \text { International License (CC BY- } \\
\text { NC-ND) (http://www.karger.com/Services/OpenAccessLicense). } \\
\text { Usage and distribution for commercial purposes as well as any dis- } \\
\text { tribution of modified material requires written permission. }\end{array}$ \\
\hline
\end{tabular}


virals are effective against specific viruses, including the herpes simplex virus and influenza virus, PMs have different mechanisms of action (inhibiting virus adsorption and entry) and are effective against a wide variety of viruses. The in vitro antiviral activities of PMs have been investigated and reported for different virus types [12].

PMs possess antibacterial effects against not only common bacteria but also methicillin-resistant Staphylococcus aureus (MRSA) and vancomycin-resistant S. aureus. The addition of oxacillin to PM compounds has synergistic antibacterial effects [13]. The addition of triclosan can evoke greater, more widespread antibacterial and antifungal effects [14]. Mixture ratios are carefully chosen such that positive effects are not blocked. We have named our antibacterial and antiviral product virus block (VB) and have acquired patents and a registered trademark. VB is a mixture of vanadyl (IV) sulfate $\left(\mathrm{VOSO}_{4}\right), \mathrm{PM} 2, \mathrm{PM} 3$, oxacillin, and triclosan (Japan registration No. 5953207, Japan patent Nos. 5279973, 5314218, and 5314219).

In terms of practical applications, we have begun to verify the effects of incorporating these active compounds into moist hand towels to improve hand hygiene.

In the present study, we examined the physical properties and stability of VB and of the 5 components found in VB (the 3 PMs, the antibacterial agent, and the antiviral agent). In addition, we investigated the effects of VB on bacteria, fungi, and MRSA. Further investigation into hand hygiene was performed regarding the use of moist hand towels in daily life settings. We collected 240 specimens from 120 volunteers to investigate the effects of different types of moist hand towels on the viability of bacteria on hands.

We verified that $\mathrm{VB}$ and its 3 main components, the PM compounds, has extremely strong inhibitory effects against general bacteria found on the hands.

\section{Methods}

\section{Materials}

Two PM compounds $\left(\mathrm{Na}_{2}\left[\mathrm{SbW}_{9} \mathrm{O}_{34}\right] \cdot 19 \mathrm{H}_{2} \mathrm{O}\right.$ and $\mathrm{K}_{11} \mathrm{H}\left[(\mathrm{VO})_{3}(\mathrm{~S}\right.$ $\left.\left.\mathrm{bW}_{9} \mathrm{O}_{33}\right)_{2}\right] \cdot 27 \mathrm{H}_{2} \mathrm{O}$ ) were synthesized according to methods described in a previous study [15]. The Research Organization of Biological Activity was assigned to synthesize a portion of these compounds. Commercially available forms of $\mathrm{VOSO}_{4} \cdot 5 \mathrm{H}_{2} \mathrm{O}$ (Kanto Chemical, Tokyo, Japan), triclosan (Wako Pure Chemical Industries, Tokyo, Japan), and oxacillin (Biotech Lab, Tokyo, Japan) were used. These 5 materials were mixed in the Research Organization of Biological Activity laboratory in the weight proportion PM1 $\left(\mathrm{VOSO}_{4} \cdot 5 \mathrm{H}_{2} \mathrm{O}\right): \mathrm{PM} 2\left(\mathrm{Na}_{2}\left[\mathrm{SbW}_{9} \mathrm{O}_{34}\right] \cdot 19 \mathrm{H}_{2} \mathrm{O}\right): \mathrm{PM} 3\left(\mathrm{~K}_{11} \mathrm{H}\left[(\mathrm{VO})_{3}(\mathrm{~S}\right.\right.$ $\left.\left.\left.\mathrm{bW}_{9} \mathrm{O}_{33}\right)_{2}\right] 27 \mathrm{H}_{2} \mathrm{O}\right)$ :triclosan:oxacillin = 7:270:30:200:150 $(\mu \mathrm{g} / \mathrm{mL})$, and the resulting mixture was named VB and used in tests. Safety studies have been conducted with formulations of these 5 reagents at a third-party institution. Moreover, PM1:PM2:PM3 prepared in the same ratio as above was designated herein as PM. The solutions used included groundwater (GW), ion-exchange water (IEW), and reverse osmosis (Elix) water. Some companies that manufacture moist hand towels use GW for cleansing, and thus, GW was added as a test material in the present study.

The bacterial and fungal species used to determine antimicrobial activity were as follows: (1) Pseudomonas aeruginosa NBRC13275, S. aureus NBRC13276, and Escherichia coli NBRC3972 and (2) Candida albicans NBRC1594. Mitsubishi Pencil Co. possesses these strains, so the investigations into the antimicrobial effects were performed in the company's internal facilities.

For hand hygiene tests, 3 types of moist hand towels were fabricated by FSX Inc.: common hand towels, hand towels supplemented with 3 PMs, and hand towels supplemented with VB. Furthermore, commercially available ethanol-containing moist hand towels were purchased and also included in the tests.

Live bacteria were collected from the hands of volunteers using swabs (Forensic Swab, Ref: 80.629.001, Sarstedt KK). The agar medium used was a standard medium for general viable bacteria.

\section{Methods}

VB Stability Tests

Samples of VB were dissolved in 2 types of water (GW and IEW), maintained at either room temperature $\left(23 \pm 3^{\circ} \mathrm{C}\right)$ or $50^{\circ} \mathrm{C}$ and extracted over time $(0,4,8$, or 12 weeks after generating the solution). Inductively coupled plasma atomic emission spectroscopy was used to analyze metal ion concentrations in the VB solution (Table 1; Model SPECTROBLUE, made by SPECTRO Analytical Instruments $\mathrm{GmbH}$ and purchased from Hitachi HighTech Science Corp.). Directly before the measurements, VB samples were passed through a $0.45-\mu \mathrm{m}$-pore filter and placed into the measurement apparatus. Seven metal ions were measured $(\mathrm{Ca}$, $\mathrm{K}, \mathrm{Mg}, \mathrm{Na}, \mathrm{Sb}, \mathrm{V}$, and $\mathrm{W}$ ), and the results are displayed as ppm.

\section{Antimicrobial Effects of VB}

Separate PM and VB solutions were prepared with GW, IEW, and Elix and maintained at room temperature or $50^{\circ} \mathrm{C}$; an aliquot of each solution was taken at each set time point. These aliquots were inoculated with bacteria or fungi, and the viable bacterial (or fungal) count was determined at each set time point using the agar culture method. Flat agar petri dishes ( 90 -mm diameter) were prepared using soybean casein digest agar medium for bacterial group tests and glucose peptone agar medium for fungal group tests. After the plates were smeared with $0.1 \mathrm{~mL}$ of sample, the number of colonies formed was counted.

Tests were performed under constant temperature and humidity conditions conforming to Japanese standards concerning the testing of moist hand towels for hygienic effects as follows: after maintenance at room temperature $\left(25^{\circ} \mathrm{C}\right)$ and $90 \%$ humidity for 29 days, viable bacteria were counted using the $10 \%$ potato dextrose agar plate culture method.

Bacterial samples were collected, and normal (indigenous) bacteria counts on the hands of volunteers (employees of the Research Organization of Biological Activity) were determined before and after moist towel usage (informed consent was obtained from each volunteer). This trial was performed according to The Code of Ethics of the World Medical Association (Declaration of Helsinki). A total of 120 volunteers were included, 66 women and 54 men; the 
Table 1. List of metallic elements in each solution

\begin{tabular}{|c|c|c|c|c|}
\hline & $\begin{array}{l}\mathrm{VB1} \\
\mathrm{VOSO}_{4}\end{array}$ & $\begin{array}{l}\mathrm{VB} 2 \\
\mathrm{~K}_{11} \mathrm{H}\left([\mathrm{VO}]_{3}\left[\mathrm{SbW}_{9} \mathrm{O}_{33}\right]_{2}\right) \cdot 27 \mathrm{H}_{2} \mathrm{O}\end{array}$ & $\begin{array}{l}\mathrm{VB} 3 \\
\mathrm{Na}_{2}\left(\mathrm{SbW}_{9} \mathrm{O}_{34}\right) \cdot 19 \mathrm{H}_{2} \mathrm{O}\end{array}$ & Oxacillin \\
\hline $\begin{array}{l}\mathrm{Ca} \\
\mathrm{K} \\
\mathrm{Mg} \\
\mathrm{Na} \\
\mathrm{Sb} \\
\mathrm{V} \\
\mathrm{W}\end{array}$ & 0 & 0 & 0 & 0 \\
\hline
\end{tabular}

VB, virus block.

mean age was 47.02 years for women (range 21-69 years) and 34.35 years for men (range 19-75 years), with an overall mean age of 41.22 years. The population was divided such that each group was similar in age, and tests were performed for each group.

Samples of indigenous bacteria from the palms were collected using a swab, which were individually sealed in a sterile case. The swab specimens were transported to the Research Organization of Biological Activity. Using aseptic equipment, swabs were suspended in $1 \mathrm{~mL}$ of phosphate-buffered saline. Next, $0.1 \mathrm{~mL}$ of this bacterial solution was spread onto a standard agar petri dish and incubated for $48 \mathrm{~h}$ at $35^{\circ} \mathrm{C}$. Subsequently, the number of colonies was counted. For specimens that could not be counted due to saturation of colony numbers, the bacterial solution was diluted 10- or 100-fold with phosphate-buffered saline and then retested.

\section{Statistical Analysis}

The mean and SD are shown for each experimental test result. Significant differences between groups were determined using one-way analysis of variance.

\section{Results}

VB Stability Tests (Table 1, Fig. 1a, b)

Table 1 shows the chemical formulas and included metal ions for each of the VB components, namely, VB1 $\left(\mathrm{VOSO}_{4}\right), \mathrm{VB} 2\left(\mathrm{~K}_{11} \mathrm{H}\left[(\mathrm{VO})_{3}\left(\mathrm{SbW}_{9} \mathrm{O}_{33}\right)_{2}\right] \cdot 27 \mathrm{H}_{2} \mathrm{O}\right), \mathrm{VB} 3$ $\left(\mathrm{Na}_{2}\left[\mathrm{SbW}_{9} \mathrm{O}_{34}\right] \cdot 19 \mathrm{H}_{2} \mathrm{O}\right)$, and oxacillin (triclosan was not tested, as it contains no metal ions). In preliminary experiments, it has been confirmed that triclosan has no effect on metallic ions.

Fig. 1. a Stability of PM compounds in VB aqueous solution (changes in metal ion concentrations over time at room temperature). b Stability of PM compounds in VB aqueous solution (changes in metal ion concentrations over time at $50^{\circ} \mathrm{C}$ ). Contorl indicates the metallic ions included in GWs alone. Similar mea-
It has been confirmed that triclosan has no effect on metallic ions. Figure $1 \mathrm{a}, \mathrm{b}$ shows the changes over time ( 0 , 4,8 , and 12 weeks, respectively) in metal ion concentrations after the aqueous solutions were placed at room temperature or $50^{\circ} \mathrm{C}$.

VB and PM-3 do not contain $\mathrm{Ca}$ or $\mathrm{Mg}$, and therefore, these metal ions were not detected when these compounds were dissolved in IEW; however, these elements were detected in the GW solution, suggesting that they were preexisting in the GW. After storage for 8 weeks at $50^{\circ} \mathrm{C}$, GW solution was found to have decreased concentrations of $\mathrm{Ca}$ and $\mathrm{W}$. This finding might have been due to the generation of certain substances that reacted with the ions and other substances in the GW. However, GW solution stored for 8 weeks at $50^{\circ} \mathrm{C}$ had low but stable levels of $\mathrm{Sb}$ (which forms a cluster structure with W), indicating the possibility that changes occurred in the cluster structure itself. Regarding the other metal ions, stable concentrations were maintained over 12 weeks based on the concentrations at time zero, and there were virtually no temperature effects. These results demonstrate that each separate chemical compound did not undergo chemical reaction or dissolution. Thus, we considered that the ideal solution in which to dissolve VB and PM3 should contain few minerals and be as pure as possible, and the compounded solutions should be maintained at environmental conditions found in daily life $\left(50^{\circ} \mathrm{C}\right.$ and below).

surements were performed twice, resulting in both values that were not different; therefore, the first measurement is shown. VB, virus block; PM3, polyoxometalate 3 .

(For figure see next pages.) 

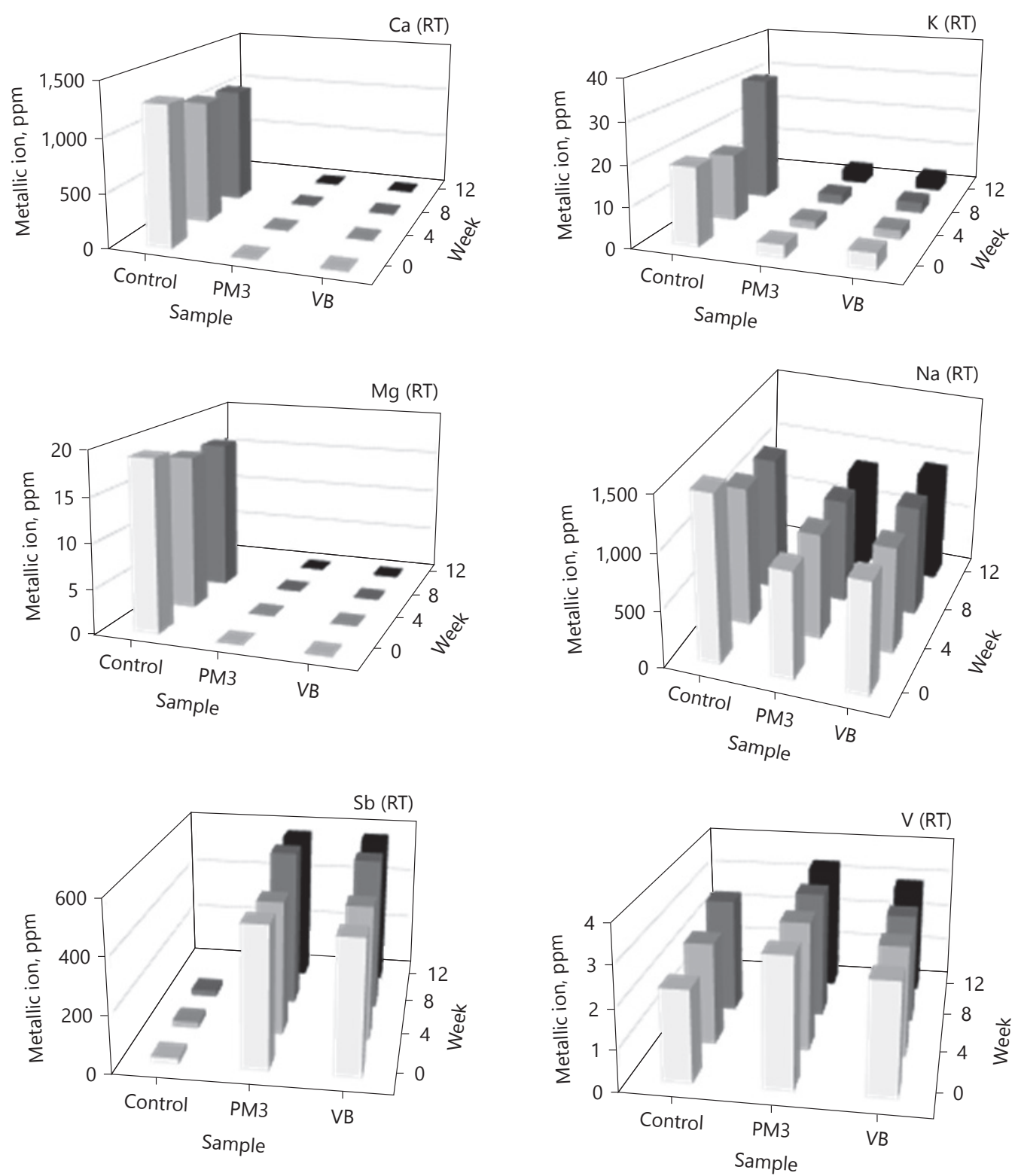

a

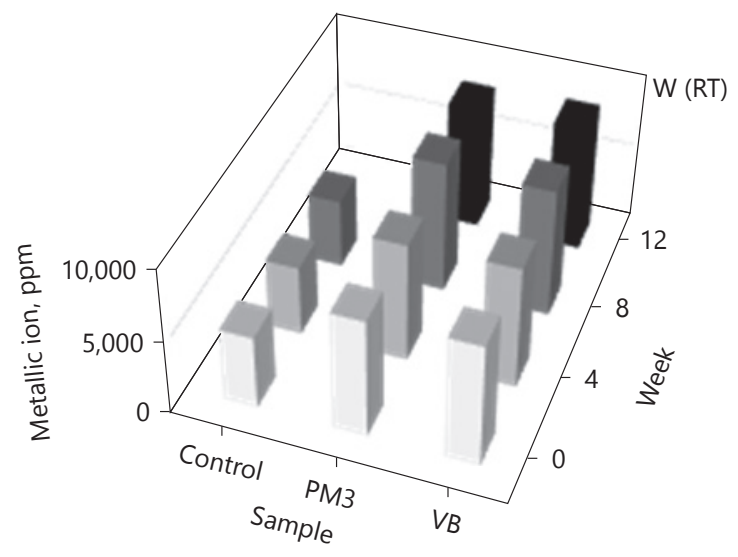



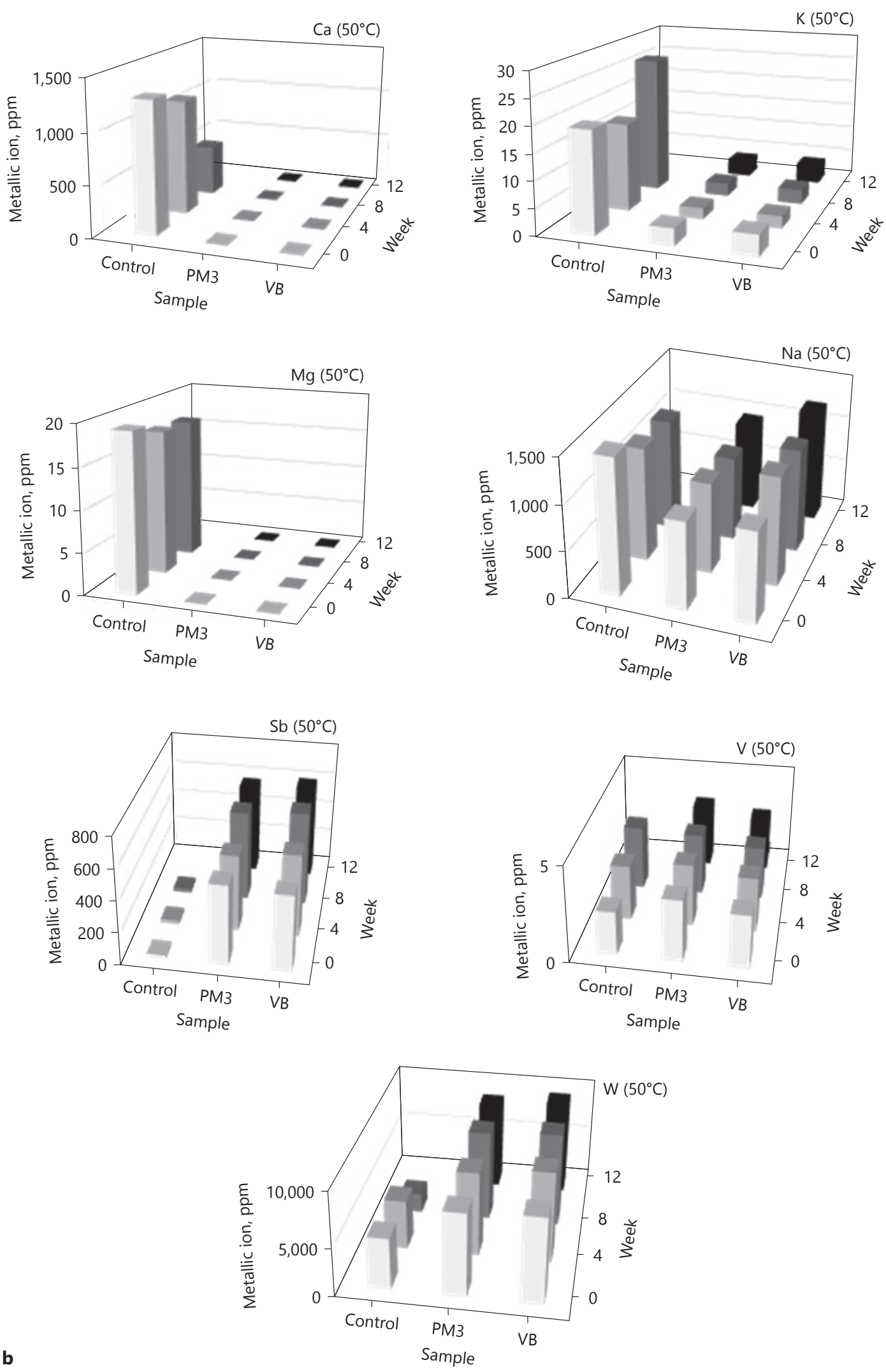

1

b 


\section{Antimicrobial Effects of VB}

Effects against Bacteria and Fungi

VB samples dissolved in 3 different kinds of water (GW, IEW, and Elix) and maintained at either room temperature or $50^{\circ} \mathrm{C}$ were tested for changes over time $(2,4$, and 8 weeks from the time the solution was prepared) in antimicrobial effects against bacteria and fungi. After bacteria and fungi were added to each aged solution, the viable organism count was investigated for changes over time $(1,2$, 3,7 , and 14 days; Fig. 2a, b, 3a, b). The numbers in the figures (vertical axes) indicate bacteria count per $0.1 \mathrm{~mL}$.

The 3 types of water with no VB had almost no effect on bacteria count, and there were no differences between maintenance at room temperature or $50^{\circ} \mathrm{C}$. Bacterial and fungal counts after storage for 8 weeks and incubation for various times after microbial addition ranged from 15,000 to 20,000 and higher.

At time points at least $2 \mathrm{~h}$ after the addition of microbes, the groups containing VB showed stable antimicrobial effects without the influence of storage time or water quality. These effects were more consistent at $50^{\circ} \mathrm{C}$ than at room temperature.

The same tests were performed for fungi; however, VB dissolved in GW had no inhibitory effects on fungi. Stable antimicrobial (antifungal) effects of VB were observed for the other test conditions (VB dissolved in IEW or Elix and maintained at room temperature or $50^{\circ} \mathrm{C}$ ), with the exception of no antifungal activity of $\mathrm{VB}$ dissolved in IEW and stored for 8 weeks at room temperature.

\section{Effects against Bacillus Cereus}

The bacterial count for the control group was between 19,000 and 20,000 at the start time and increased to a mean of 186,600 after $18 \mathrm{~h}$. In the VB-supplemented group, the mean was suppressed 3 orders of magnitude to 210 (Fig. $4 ; n=3$ ).

\section{Effects against MRSA}

Although the control had an initial bacterial count of 73,000 , this count increased to 10 million after $20 \mathrm{~h}$. In the VB group diluted 100 -fold, the bacterial count was suppressed to $14 / 100,000$, and this suppression was maintained at 4/1,000 for the 10,000-fold dilution; thus, bacterial counts were lower than at the start time (Fig. 5).

Fig. 2. a VB effects against bacteria (changes over time after storing VB solution at room temperature and further modifying the solution and changes over time after the addition of bacteria). $\mathbf{b} \mathrm{VB}$ effects against bacteria (changes over time after storing VB solution at $50^{\circ} \mathrm{C}$ and further modifying the solution and changes over
Constant Temperature and Humidity Test (Using an Examination Method that Conforms to the Japanese Ministry of Health, Labor, and Welfare Standards Concerning the Testing of Moist Hand Towels for Hygienic Effects)

Tests were performed in accordance with the standards concerning the hygienic effects of moist hand towels as promulgated by the Japan Ministry of Health, Labor, and Welfare [16]. The viable bacteria count increased nearly 900 -fold at approximately 1 month for moist hand towels commonly used in Japan; conversely, VB-supplemented hand towels showed lower bacteria counts at 1 month than on day 1 (Fig. 6).

Investigation of Bacteria Count on Hands before and after Moist Hand Towel Usage

Swab specimens of bacteria on the hands were collected before and after the use of 4 types of moist hand towels. Each type of towel was used by 30 persons; in other words, the 120 participating volunteers were divided into 4 groups, and bacteria counts were calculated for 240 specimens.

Figure 7 shows bacterial counts before and after the use of the 4 types of hand towels. Before using a hand towel, bacteria counts were roughly the same for all 4 groups, with an overall mean of $949.5 \pm 8.5$. Wiping hands with a hand towel moistened with ordinary water reduced the bacterial count to $71 \%$ of that before towel usage (set to $100 \%)$. Commercially available ethanol-added hand towels reduced the bacterial count by $43 \%$. In contrast, residual bacteria were reduced to just $5.4 \%$ in the PMsupplemented group and to $0.8 \%$ in the VB-supplemented group. Images show representative examples of propagated bacteria within petri dishes (Fig. 8).

\section{Discussion}

Existing antiviral agents act mainly against herpes and influenza viruses; their mechanism of action involves suppressing viral propagation by working as transcription terminators after entering the cell. However, such agents have various problematic issues, including the appearance of resistant strains, and there is a desire for agents with different mechanisms of action. Meanwhile,

time after the addition of bacteria). Similar measurements were performed twice, resulting in both values that were not different; therefore, the first measurement is shown. VB, virus block; IEW, ion-exchange water.

(For figure see next pages.)
In vitro Antimicrobial Effects of VB, Which Contains Multiple PM
Pharmacology 2019;104:98-112 DOI: $10.1159 / 000500897$ 

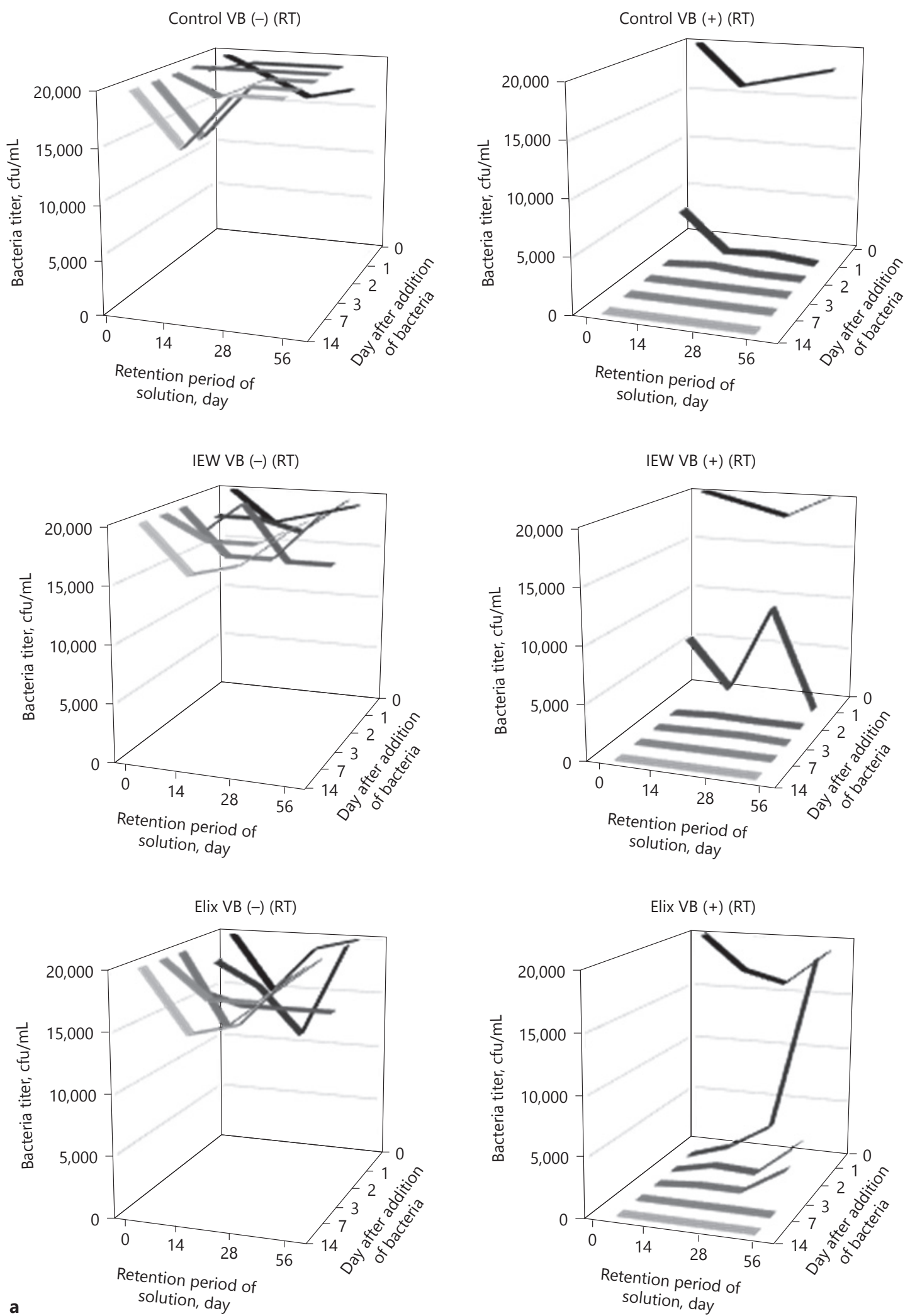

2 

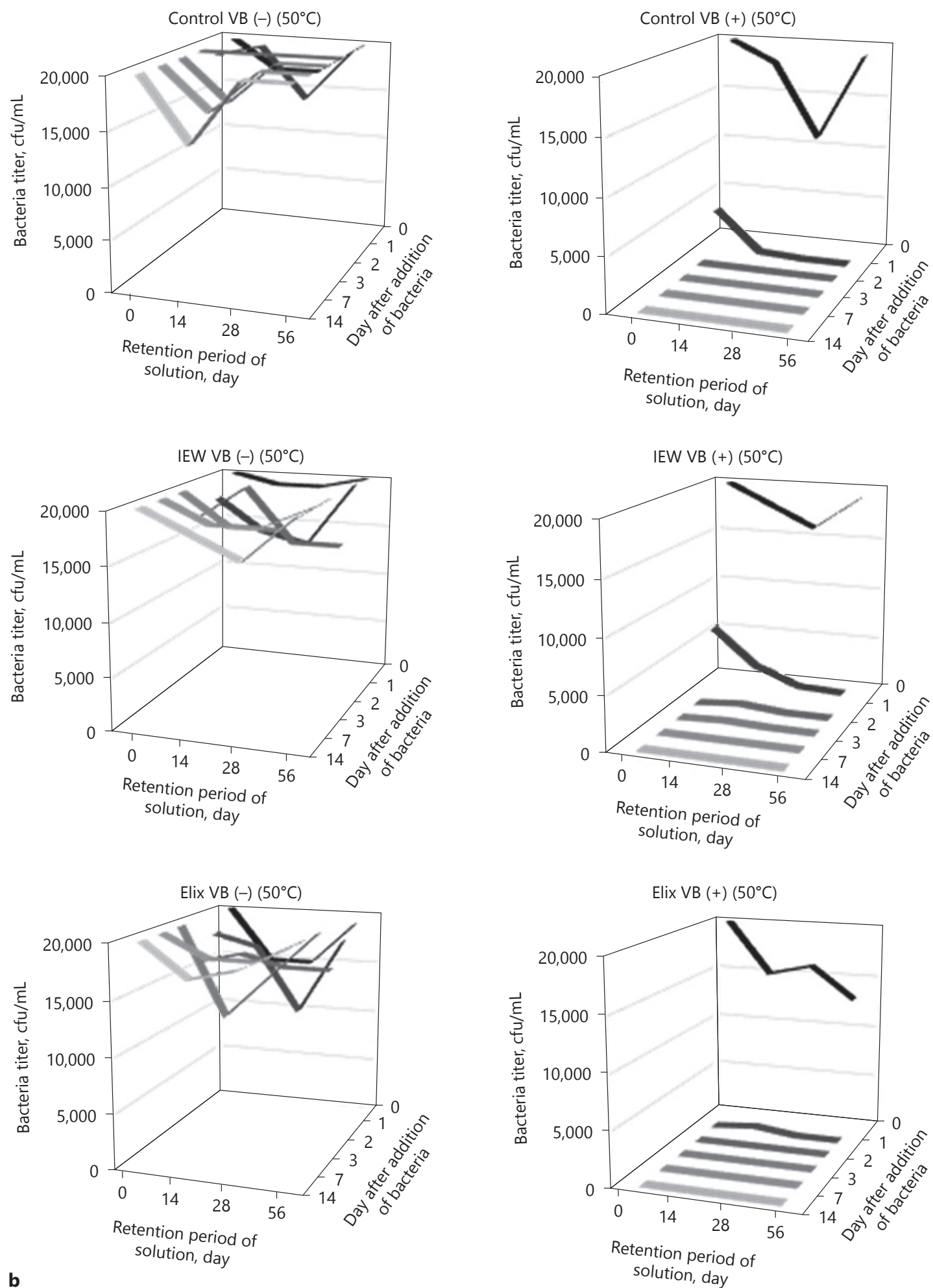

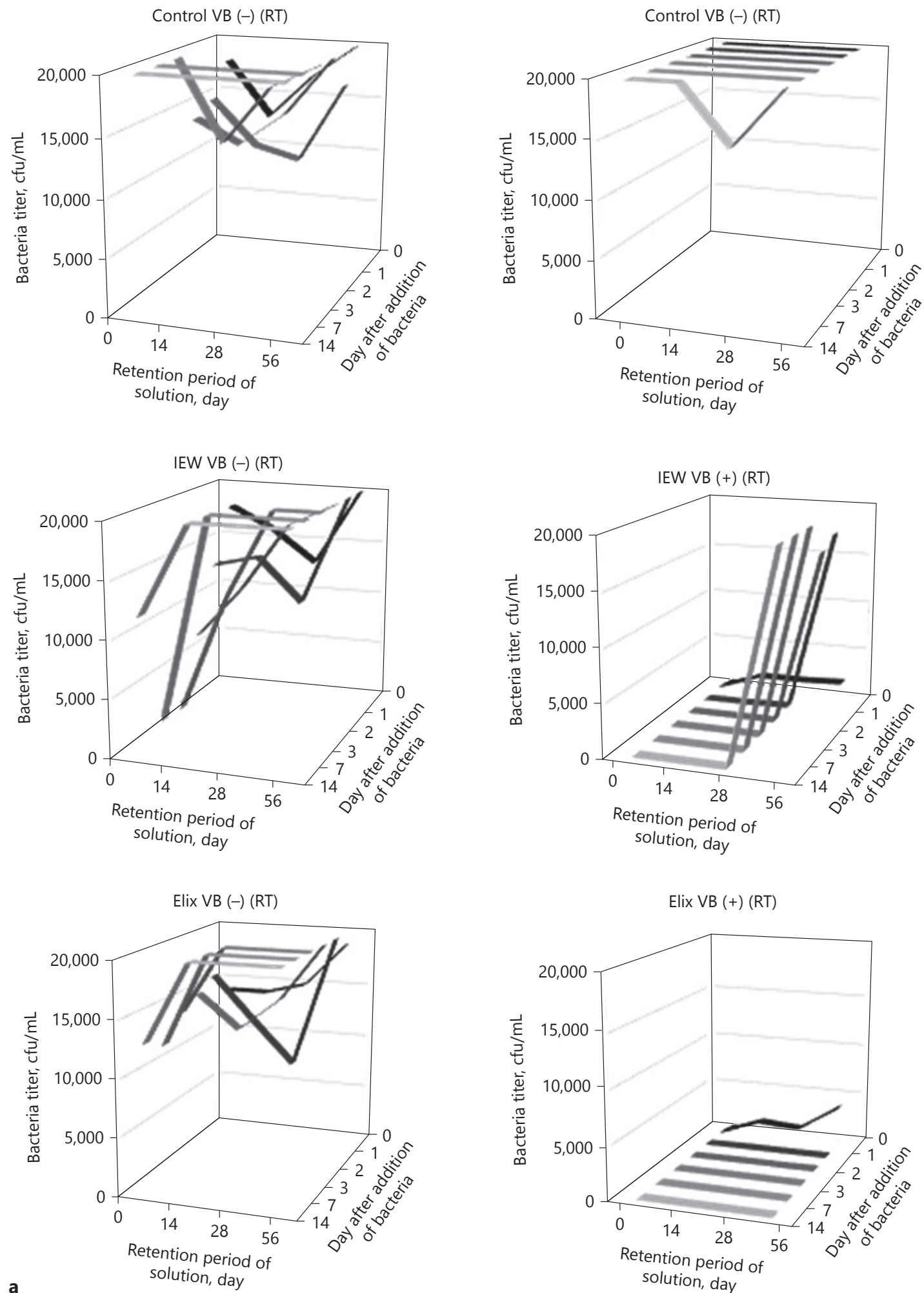

3

(For figure $3 b$ and legend see next page.) 

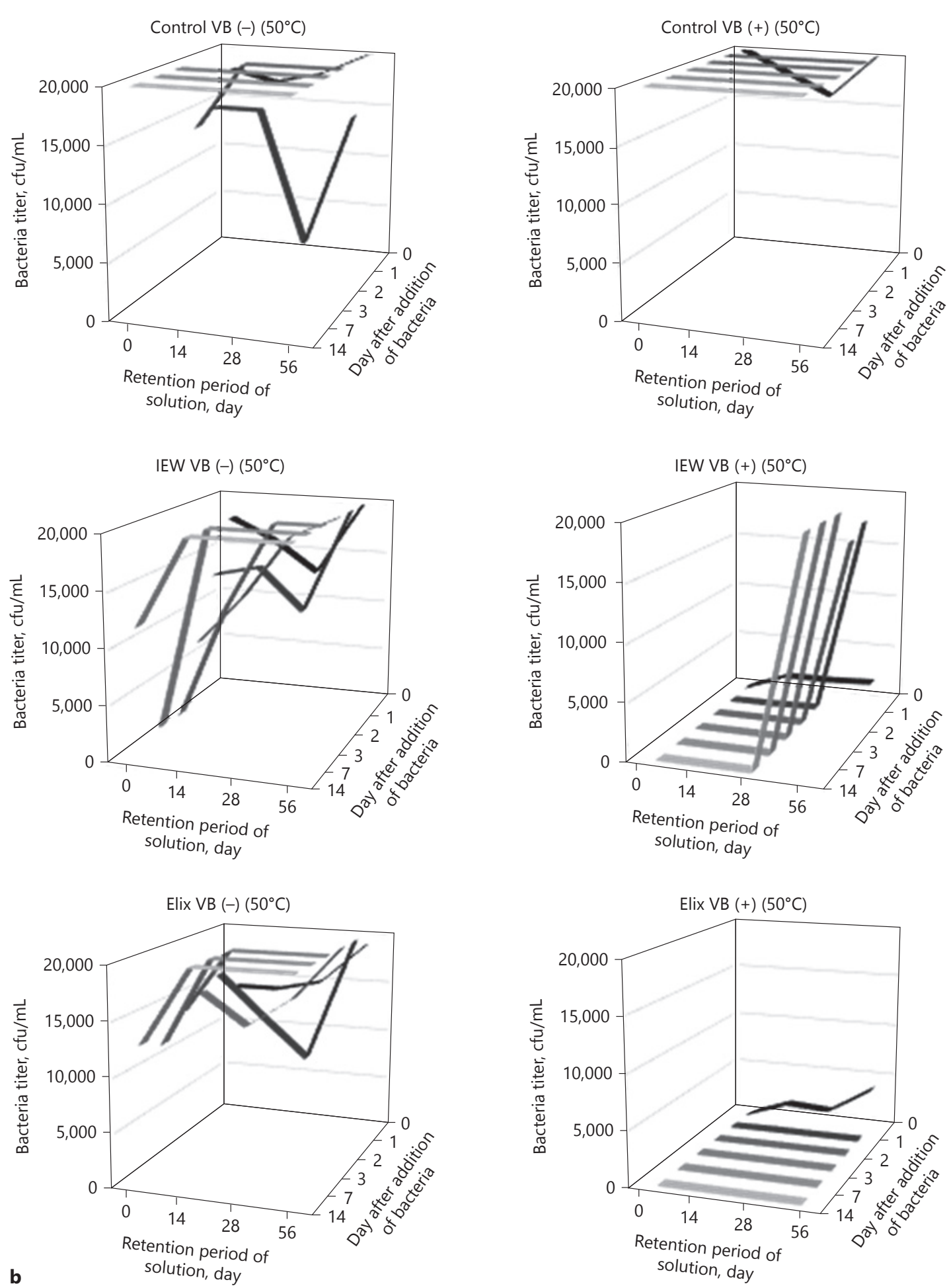

Fig. 3. a VB effects against fungi (changes over time after storing VB solution at room temperature and further modifying the solution and changes over time after the addition of fungi). $\mathbf{b}$ VB effects against fungi (changes over time after storing VB solution at $50^{\circ} \mathrm{C}$ and further modifying the solution and changes over time after the addition of fungi). Similar measurements were performed twice, resulting in both values that were not different; therefore, the first measurement is shown. VB, virus block; IEW, ion-exchange water. 
Fig. 4. VB effects against Bacillus cereus (after $B$. cereus cultivation $[n=3]$; colony number). VB, virus block.
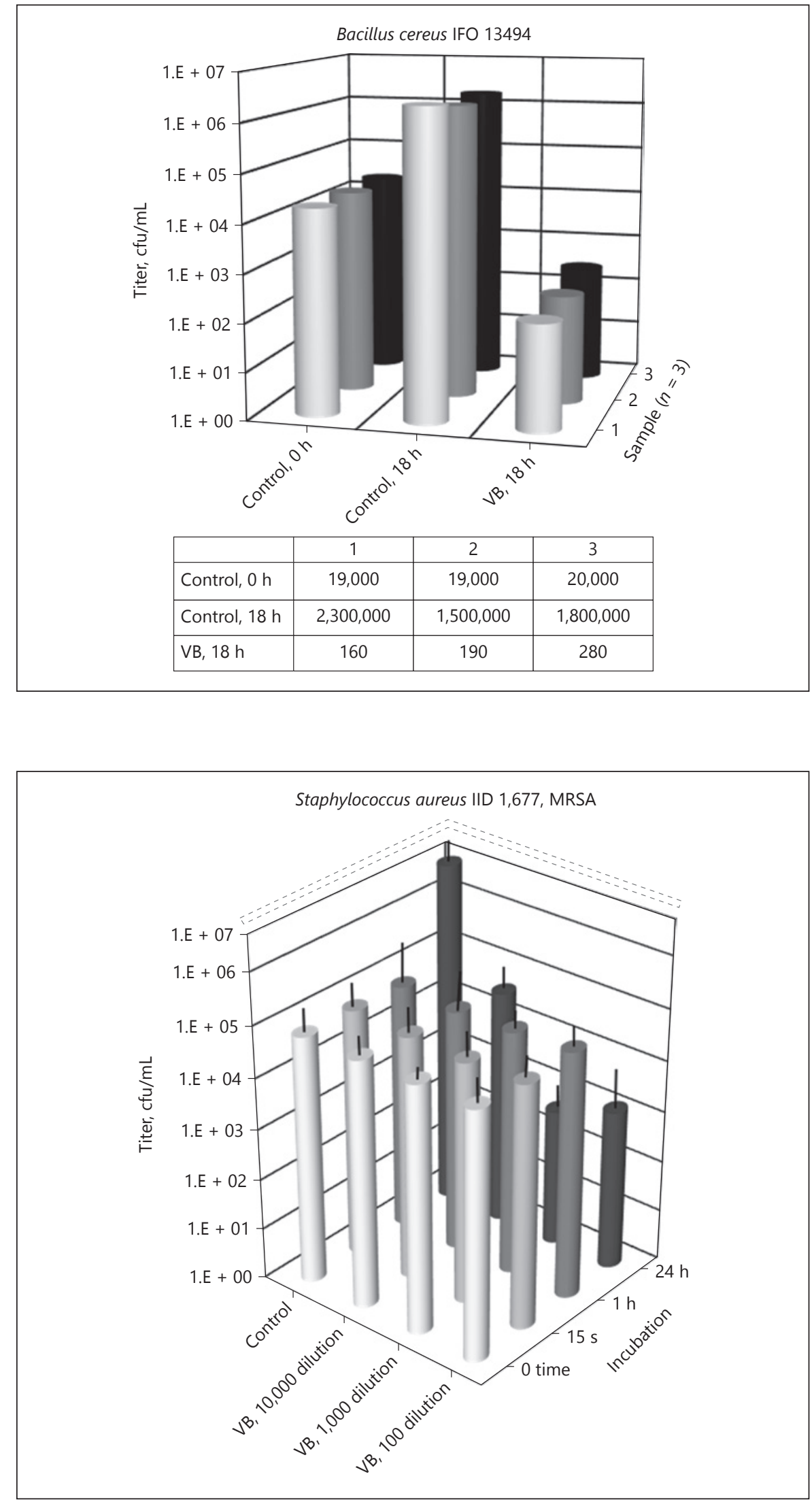

Fig. 5. VB effects against Staphylococcus aureus IID 1677 (MRSA; effects due to dilutions of VB solution at $15 \mathrm{~s}, 1 \mathrm{~h}$, and $24 \mathrm{~h}$ of MRSA cultivation). VB, virus block; MRSA, methicillin-resistant Staphylococcus aureus. 
Fig. 6. VB antiviral effects at constant temperature and humidity (test method according to the Japanese Ministry of Health, Labor, and Welfare standards concerning the testing of moist hand towels for hygienic effects). VB, virus block.

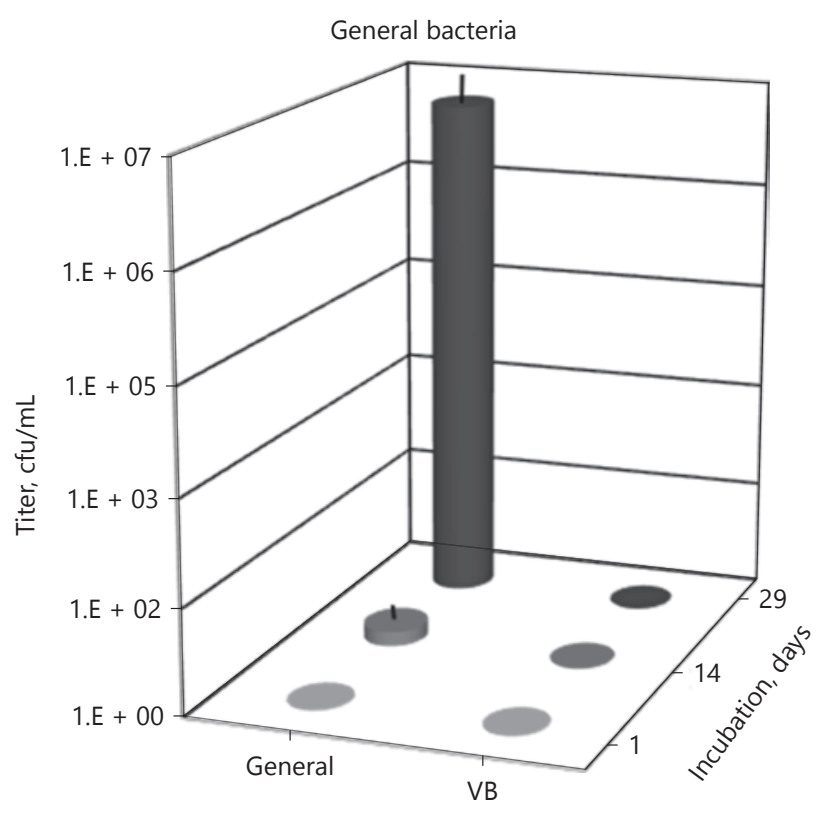

\begin{tabular}{|l|c|c|c|}
\hline & 1 day & 14 days & 19 days \\
\hline General & 27,200 & 681,000 & $24,030,000$ \\
\hline VB & 12,900 & 17,050 & 4,800 \\
\hline
\end{tabular}

although there are certain antiviral agents that show efficacy against human immunodeficiency virus, severe acute respiratory syndrome, and so on, there is concern about their toxicity, narrow therapeutic indexes, and side effects.

PM compounds, conversely, work at the cell surface to block virus adsorption and invasion $[10,11]$. As they have high affinity for virions, they have been found to form complexes and block infection [11]. In terms of their antimicrobial effects, they have been shown to be effective against MRSA and vancomycin-resistant $S$. aureus, and synergistic effects with concomitant oxacillin have also been demonstrated [13].

These characteristics give VB broad-ranging antimicrobial and antiviral activity against not only the influenza virus but also bacteria, fungi, Bacillus cereus, and MRSA. No similar effects have been demonstrated for other compounds, and we considered that our results have considerable significance regarding practical applications.

To generate a useful VB mixture, tests were needed to assess the stability of its physical properties. We thus performed stability tests for VB (a mixture of 5 components) and for PM compounds alone (a mixture of 3 compo- nents). The measurement of free metal concentrations in solution enables an estimate of compound modification and deterioration. The elements contained in VB showed almost no changes over an approximately 3 -month period, demonstrating the stability of each of these elements. Furthermore, no differences were found after long-term storage at different temperatures, namely, room temperature and $50^{\circ} \mathrm{C}$; practically, we considered there are no special concerns regarding temperature. However, for GW and other possible solutions that may contain minerals, long-term maintenance at high temperatures of, for example, $50^{\circ} \mathrm{C}$ may lead to some component modification. For these reasons, the use of high-purity water is important, as is preventing exposure to high temperatures over a long period of time.

With respect to the antibacterial and antifungal effects of VB effects, the quality of water used in the VB solution might have had an effect. Deionized water or water of even higher quality is desirable, but this will involve a trade-off with expense in practical applications.

Japan has established standards regarding the testing of moist hand towels for hygienic effects, and we performed tests at constant temperature and humidity in our present research using examination methods that con- 
Fig. 7. Investigation of hand sterilization effects (viable bacteria removal) due to the usage of VB-supplemented moist hand towels. PM, polyoxometalate; VB, virus block.

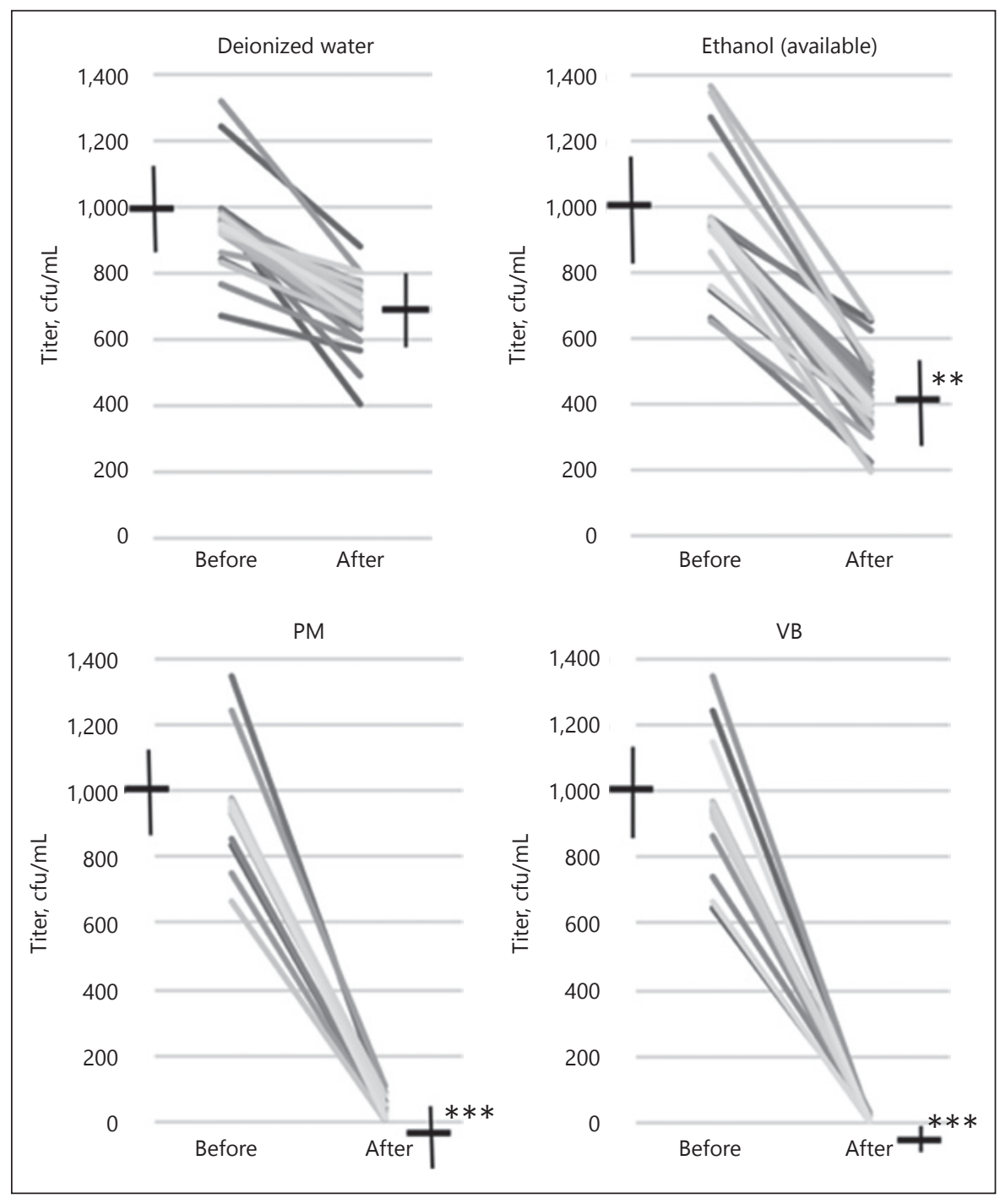

form to these standards. Ordinarily, bacteria and other microorganisms propagate logarithmically, but in the presence of VB, suppressive effects were apparent on the first day of treatment, while on day 29 , bacteria counts were suppressed to starting levels. We considered this is proof of the sustainability of the effects of VB.

Moist hand towel manufacturers in Japan are instructed by the Ministry of Health, Labor, and Welfare to use a chlorine agent in their hand towels, as this agent acts as a disinfectant. Certainly, hypochlorous acid does show strong bactericidal and bleaching effects; the fact that it is also low-priced means that it continues to be widely used. Its effects, however, are relatively short term. Moreover, the moist hand towels themselves, as well as anything else that contacts hypochlorous acid, can corrode, the stock solution emits odors, and there may be unfavorable ef- fects on the human body. Considering the need for more sustainable bactericidal effects, it is necessary to develop novel substances with new types of efficacy. In the future, we considered that the use of triclosan should be avoided. Therefore, we started to investigate the use of polyhexamethylene biguanidine as an alternative to be formulated into PM-compounds.

\section{Conclusions}

In this study, we verified the effects on hand hygiene with the cooperation of 120 volunteers. We found that the use of a commercially available moist hand towel removed approximately $28 \%$ of adhesive bacteria, whereas the ethanol-supplemented towel removed $43 \%$. Mean- 
while, adhesive bacteria counts were $5.4 \%$ of the test start quantity after using a hand towel containing the 3 types of PM and $0.8 \%$ of the test start quantity after using those containing VB. Thus, in this practical application, VB and PM showed sufficient positive effects. In this study, we did not investigate the individual effects of oxacillin or triclosan; however, considering that there was a small difference between the results for the 5-component VB and the 3 types of PM, we think that the antimicrobial effects of oxacillin or triclosan constitute only a small proportion of the total effect and that the PM compounds are chiefly responsible for the observed effect. Although these results are for so-called "indigenous bacteria," given that a variety of pathogenic microorganisms may be included in this population, we conclude that moist hand towels containing VB or PM are efficacious at removing or killing these pathogens.

The broad-ranging antiviral effects of PM compounds have been verified previously. In this study, we confirmed that the VB formula has not only antiviral effects but also broad-ranging antimicrobial effects, even against MRSA. Furthermore, if mixed with hypochlorous acid at optimum concentrations, $\mathrm{VB}$ can provide persistence to the individual effects of hypochlorous acid. Our results also suggest that adding VB to moist hand tissues enables them to serve as effective hygienic tools in ordinary daily life.

\section{Acknowledgments}

The authors thank Akiko Okayama, Yusuke Soga, Yoshiharu Konno, and all the staff at FSX, Inc., for valuable technical support and Takashi Umeno and Yasuaki Ogiwara at Mitsubishi Pencil Co., Ltd., for technical support and discussion.

\section{Statement of Ethics}

This study was conducted in accordance with the ethical regulations of FSX. Informed consent was obtained from each volunteer who participated.

\section{Disclosure Statement}

The authors declare that they have no competing interests.

\section{Funding Sources}

This research was supported by FSX, Inc., (grant number 160401). This grant was used to purchase reagent consumables.

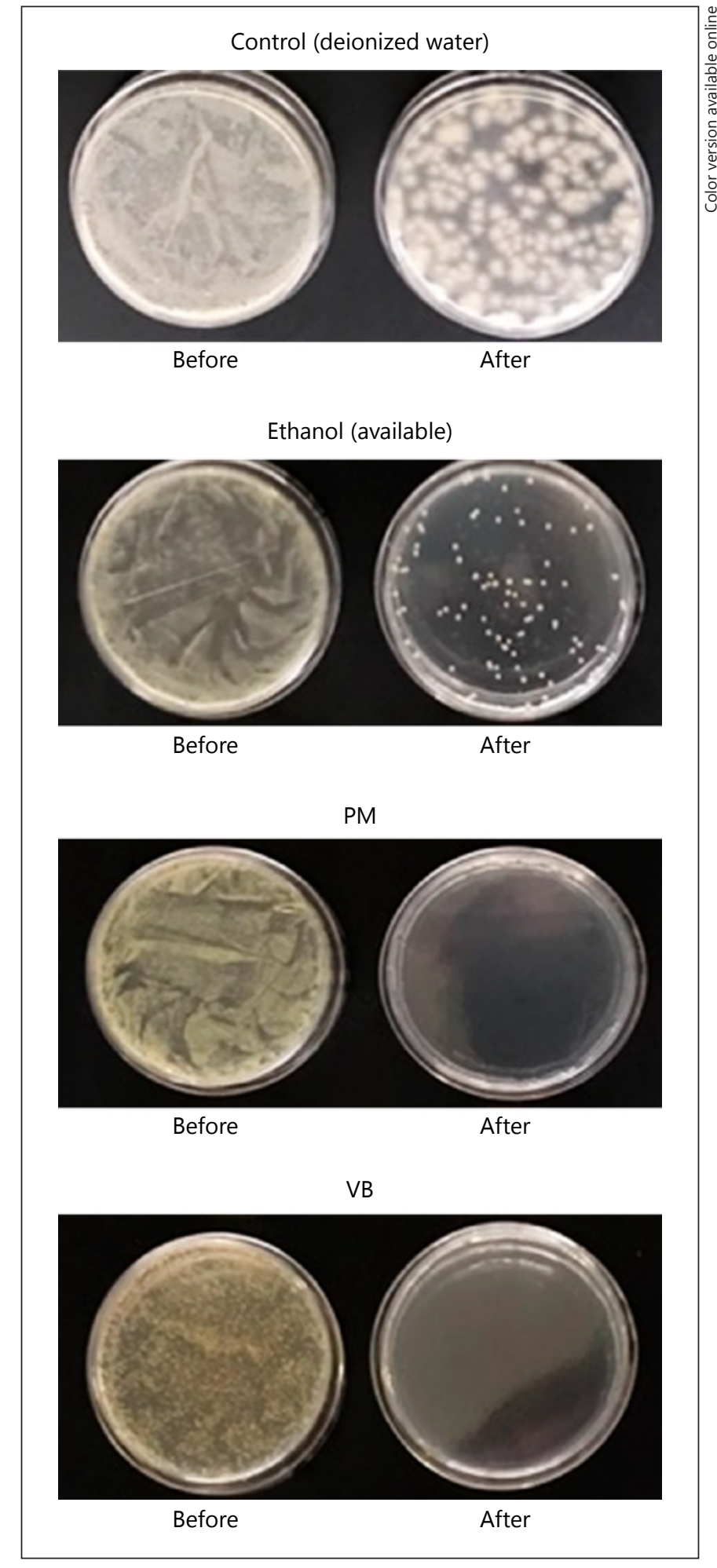

Fig. 8. Investigation of hand sterilization effects (viable bacteria removal) due to the usage of VB-supplemented moist hand towels (images of representative cases). PM, polyoxometalate; VB, virus block.
In vitro Antimicrobial Effects of VB, Which Contains Multiple PM
Pharmacology 2019;104:98-112 DOI: $10.1159 / 000500897$ 


\section{Author Contributions}

All authors contributed to this work. K.D., T.M., and K.F.: carried out the experiments and analyzed the results. All authors interpreted the results and designed the research strategy. K.D. and T.M.: prepared the manuscript. All authors read and approved the final manuscript.

\section{Consent for Publication}

Not applicable.

\section{Availability of Data and Material}

All data generated or analyzed during this study are included in this published article.

\section{References}

1 Yamase T. Polyoxometalates active against tumors, viruses, and bacteria. Prog Mol Subcell Biol. 2013;54:65-116.

2 Inouye Y, Tokutake Y, Yoshida T, Seto Y, Hujita $\mathrm{H}$, Dan $\mathrm{K}$, et al. In vitro antiviral activity of polyoxomolybdates. Mechanism of inhibitoryeffectofPM-104(NH4)12H2(Eu4(MoO4) (H2O)16(Mo7O24)4).13H2O on human immunodeficiency virus type 1 . Antiviral Res. 1993 Apr;20(4):317-31.

3 Ikeda S, Nishiya S, Yamamoto A, Yamase T, Nishimura C, De Clercq E. Activity of the Keggin polyoxotungstate PM-19 against herpes simplex virus type 2 infection in immunosuppressed mice: role of peritoneal macrophage activation. J Med Virol. 1993 Nov; 41(3):191-5.

4 Yamase T, Fukuda N, Tajima Y. Synergistic effect of polyoxotungstates in combination with beta-lactam antibiotics on antibacterial activity against methicillin-resistant Staphylococcus aureus. Biol Pharm Bull. 1996 Mar; 19(3):459-65.

5 Shigeta S, Mori S, Watanabe J, Soeda S, Takahashi K, Yamase T. Synergistic anti-influenza virus $A(\mathrm{H} 1 \mathrm{~N} 1)$ activities of PM-523 (polyoxometalate) and ribavirin in vitro and in vivo. Antimicrob Agents Chemother. 1997 Jul;41(7):1423-7.

6 Fukuda N, Yamase T. In vitro antibacterial activity of vanadate and vanadyl compounds against Streptococcus pneumoniae. Biol Pharm Bull. 1997 Aug;20(8):927-30.

7 Shigeta S, Yamase T. Current status of antiSARS agents. Antivir Chem Chemother. 2005;16(1):23-31.

8 Fukuma M, Seto Y, Yamase T. In vitro antiviral activity of polyoxotungstate (PM-19) and other polyoxometalates against herpes simplex virus. Antiviral Res. 1991 Dec;16(4):32739.

9 Dan K, Miyashita K, Seto Y, Fujita H, Yamase T. The memory effect of heteropolyoxotungstate (PM-19) pretreatment on infection by herpes simplex virus at the penetration stage. Pharmacol Res. 2002 Oct; 46(4):357-61.

10 Dan K, Miyashita K, Seto Y, Fujita H, Yamase T. Mechanism of the protective effect of heteropolyoxotungstate against herpes simplex virus type 2. Pharmacology. 2003 Feb;67(2): 83-9.

11 Dan K, Yamase T. Prevention of the interaction between HVEM, herpes virus entry me- diator, and gD, HSV envelope protein, by a Keggin polyoxotungstate, PM-19. Biomed Pharmacother. 2006 May;60(4):169-73.

12 Shigeta S, Mori S, Yamase T, Yamamoto N, Yamamoto N. Anti-RNA virus activity of polyoxometalates. Biomed Pharmacother. 2006 Jun;60(5):211-9.

13 Inoue M, Suzuki T, Fujita Y, Oda M, Matsumoto N, Iijima J, et al. Synergistic effect of polyoxometalates in combination with oxacillin against methicillin-resistant and vancomycin-resistant Staphylococcus aureus: a high initial inoculum of 1 x $108 \mathrm{cfu} / \mathrm{ml}$ for in vivo test. Biomed Pharmacother. 2006 Jun; 60(5):220-6.

14 Lilly HA, Lowbury EJ. Disinfection of the skin with detergent preparations of Irgasan DP 300 and other antiseptics. BMJ. 1974 Nov; 4(5941):372-4.

15 YamaseT,Botar B, IshikawaE, Fukaya K.Chemical Structure and Intramolecular Spin-Exchange Interaction of [(VO)3(SbW9O33)2]12. ChemLett.2001;30(1):56-7.

16 The whole country moist hand towel Federation of Cooperatives. www.mhlw.go.jp/ toukei_hakusho/hakusho/kousei/1983/dl/14. pdf 